\title{
Periodontal Inflamed Surface Area Mediates the Link between Homocysteine and Blood Pressure
}

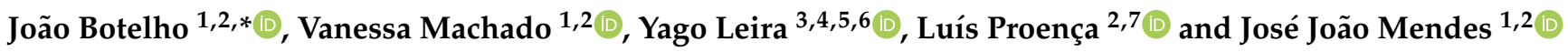 \\ 1 Clinical Research Unit (CRU), Egas Moniz Interdisciplinary Research Center, Egas Moniz-Cooperativa de \\ Ensino Superior, 2829-511 Almada, Portugal; vmachado@egasmoniz.edu.pt (V.M.); \\ jmendes@egasmoniz.edu.pt (J.J.M.) \\ 2 Evidence-Based Hub, Egas Moniz Interdisciplinary Research Center, Egas Moniz-Cooperativa de Ensino \\ Superior, 2829-511 Almada, Portugal; lproenca@egasmoniz.edu.pt \\ 3 Periodontology Unit, UCL Eastman Dental Institute and NIHR UCLH Biomedical Research Centre, \\ University College London, London WC1E 6BT, UK; y.leira@ucl.ac.uk \\ 4 Periodontology Unit, Faculty of Medicine and Odontology, University of Santiago de Compostela, \\ 15706 Santiago de Compostela, Spain \\ 5 Medical-Surgical Dentistry (OMEQUI) Research Group, Health Research Institute of Santiago de \\ Compostela (IDIS), 15706 Santiago de Compostela, Spain \\ 6 Clinical Neurosciences Research Laboratory, Health Research Institute of Santiago de Compostela (IDIS), \\ 15706 Santiago de Compostela, Spain \\ 7 Quantitative Methods for Health Research (MQIS), Egas Moniz Interdisciplinary Research Center, \\ Egas Moniz-Cooperativa de Ensino Superior, 2829-511 Almada, Portugal \\ * Correspondence: jbotelho@egasmoniz.edu.pt; Tel.: +351-212-946-800
}

Citation: Botelho, J.; Machado, V.; Leira, Y.; Proença, L.; Mendes, J.J. Periodontal Inflamed Surface Area Mediates the Link between Homocysteine and Blood Pressure. Biomolecules 2021, 11, 875. https:// doi.org/10.3390/biom11060875

Academic Editor: Atsushi Saito

Received: 8 May 2021

Accepted: 10 June 2021

Published: 12 June 2021

Publisher's Note: MDPI stays neutral with regard to jurisdictional claims in published maps and institutional affiliations.

Copyright: (c) 2021 by the authors. Licensee MDPI, Basel, Switzerland. This article is an open access article distributed under the terms and conditions of the Creative Commons Attribution (CC BY) license (https:// creativecommons.org/licenses/by/ $4.0 /)$.
Abstract: Here, we assess the association between homocysteine (Hcy) serum levels and periodontal status in a large representative sample of the National Health and Nutrition Examination Survey (NHANES). Using the 2001-2002 and 2003-2004 NHANES databases, participants with a periodontal examination, medical self-reported data, blood pressure (BP) and blood samples to determine complete blood count, C-reactive protein (CRP) and Hcy levels. We then calculated the periodontal inflamed surface area (PISA) and the periodontal epithelial surface area (PESA). Multivariable regression analysis explored the association between Hcy, periodontal measures and BP. Mediation analysis was performed to understand the effect of PISA and PESA in the link between Hcy and BP. 4021 participants fulfilled the inclusion criteria. Hcy levels showed significant correlations with systolic BP, diastolic BP, PISA, PESA and age. PESA showed to be significantly associated with Hcy both for the crude and adjusted models $(p<0.01)$, but not PISA $(p>0.05)$. In the association of Hcy with systolic BP, PISA significantly mediated $17.4 \%$ and PESA $0.9 \%$. In the association of Hcy with diastolic BP, PISA significantly mediated $16.3 \%$ and PESA $47.2 \%$. In conclusion, Hcy and periodontitis are associated. Further, both PISA and PESA significantly mediated the association of Hcy with systolic BP and diastolic BP. Future studies shall deepen the mechanisms by which Hcy levels increase in a clinical situation of periodontitis.

Keywords: periodontitis; periodontal disease; periodontal medicine; inflammation and innate immunity; cardiovascular disease(s); oral medicine

\section{Introduction}

Homocysteine (Hcy) is an amino acid synthesized as an intermediate metabolite from the methionine (Met) biosynthesis [1,2]. In plasma, 1\% of Hcy circulates in its free form while the remaining $99 \%$ is bound to proteins [3], and its concentration normally ranges between 5-15 $\mu \mathrm{mol} / \mathrm{L}$ [2]. In cases of hyperhomocysteinemia (defined as total Hcy in plasma $>15 \mu \mathrm{mol} / \mathrm{L}$ ) $[4,5]$, the main causes may be impaired metabolism of Met or defective cofactors in the remethylation to methionine pathway (involving B12 and folic acid) or the trans-sulfuration pathway (involving B6) [6]. 
Hyperhomocysteinemia has been implicated with high blood pressure (BP) [7] as the increase in Hcy levels inhibits the synthesis of endothelial nitric oxide, causing its dysfunction and damages the myocardium via the excessive production of reactive oxygen radicals $[8,9]$. Hcy was firstly introduced as a candidate in the link of periodontal and cardiovascular conditions [10], but ever since, studies on this topic have been relatively scarce.

Periodontitis is a chronic inflammatory condition of the periodontium driven by a dysbiotic plaque [11,12]. Hcy was firstly reported to be associated with periodontitis [13,14], and was suggested as an inflammatory marker of periodontitis as its levels decrease after periodontal treatment [15]. Moreover, periodontitis plays a very active role in cardiovascular illnesses whether through systemic inflammation affecting endothelial function and through vascular dysfunction caused by bacteremia and cell infiltrate secondary to periodontal microbiota [16]. Thus, a possible form of action of periodontitis emerges in the Hcy-hypertension link (i.e., mediation effect), however this has never been studied.

The primary aim of the present study was to assess the association between Hcy serum levels and periodontal parameters in a large representative sample of the National Health and Nutrition Examination Survey (NHANES). As a secondary aim, we appraised the mediation effect of periodontal measurements in the link between Hcy and BP.

\section{Materials and Methods}

\subsection{Study Design and Participants}

In this study, we performed a secondary analysis using datasets from the NHANES of 2001-2002 and 2003-2004 [17]. Data was gathered through interviews, physical and laboratory exams, and both waves have been reviewed and approved by the Centers for Disease Control (CDC) and Prevention National Center for Health Statistics Research (NCHS) Ethics Review Board. All included participants provided a written informed consent.

For the purpose of this study, the following inclusion criteria were defined: participants with 18 years old or older, undergone periodontal examination and had completed measurement of plasma Hcy. This study follows the strengthening the reporting of observational studies in epidemiology (STROBE) guideline [18] (Table S1).

\subsection{Periodontal Examination}

The periodontal examination was carried out using a partial-mouth protocol using randomly assigned quadrants (one on the upper arch, and one on the lower arch), by calibrated examiners as previously defined [19]. Three periodontal measures were registered: periodontal pocket depth (PPD), clinical attachment loss (CAL) and bleeding on probing (BOP). These measures were made at three buccal sites per tooth (mesio-, mid- and disto-buccal). The presence of periodontitis was diagnosed according to the CDC/American Academy of Periodontology (AAP) case definition [20]. Then, periodontitis was categorized as mild ( $\geq 2$ interproximal sites with CAL $\geq 3 \mathrm{~mm}$; and $\geq 2$ interproximal sites with PPD $\geq 4 \mathrm{~mm}$ (not on the same tooth) or 1 site with PPD $\geq 5 \mathrm{~mm}$ ), moderate ( $\geq 2$ interproximal sites with CAL $\geq 4 \mathrm{~mm}$ [not on the same tooth] or $\geq 2$ interproximal sites with PPD $\geq 5 \mathrm{~mm}$, also not on the same tooth) and severe ( $\geq 2$ interproximal sites with CAL $\geq 6 \mathrm{~mm}$ (not on the same tooth) and $\geq 1$ interproximal site with PPD $\geq 5 \mathrm{~mm}$ ). The overall number of participants with periodontitis was the sum of mild, moderate and severe periodontitis.

Next, we computed for each tooth the PISA and the PESA for each specific participant. PISA and PESA were used as continuous variables. PISA comprised the surface area of bleeding pocket epithelium and PESA is the root surface area of that tooth, which is covered with pocket epithelium [21,22]. PISA and PESA were calculated using a Microsoft Excel spreadsheet, in the following steps:

a. Calculation of mean CAL and gingival recession for each particular tooth;

b. Linear mean CAL and gingival recession is used to calculate PESA;

c. For each tooth, PISA is calculated through the multiplication of PESA by the proportion of sites around the tooth with BOP; 
d. The sum of all individual PISA and PESA scores, in $\mathrm{mm}^{2}$, provides an overall area, respectively, for each participant.

\subsection{Plasma Homocysteine Measurement}

For NHANES 2001, total Hcy in plasma was quantified by a fully automated fluorescence polarization immunoassay (FPIA) (Abbott Hcy IMX (HCY) assay, Abbott Laboratories, Chicago, IL, USA) [23]. For NHANES 2002 and 2003-2004, total Hcy in plasma was measured by other FPIA (Abbott Diagnostics (Abbott AxSym analyzer, Abbott ${ }^{\circledR}$ ), Abbott Laboratories, Chicago, IL, USA) [23-25]. Both methods employed the same reagent kit. Moreover, both approaches presented equivalence as the FPIA results were successfully compared to high performance liquid chromatography with fluorometric detection at $385 \mathrm{~nm}$ excitation and $515 \mathrm{~nm}$ emission [23,25]. Hyperhomocysteinemia was defined as total Hcy in plasma $>15 \mu \mathrm{mol} / \mathrm{L}[4,5]$.

In both FPIA approaches [23-25], dithiothreitol (DTT) was used to free thiol, then S-adenosyl-Hcy (SAH) hydrolase was applied to catalyze the conversion of Hcy to SAH in the presence of added adenosine. Then, FPIA was performed using a specific monoclonal antibody and fluoresceinated SAH analog tracer [24]. In the first FPIA method, total Hcy concentrations were calculated by the Abbott IMx ${ }^{\circledR}$ (Illinois, USA) using a machine-stored calibration curve, while in the second was calculated by the Abbott Axsym ${ }^{\circledR}$ (Illinois, USA) using a machine-stored calibration curve [26,27].

\subsection{Covariates}

We included sociodemographic data, including age, gender, race/ethnicity (categorized as mexican american, non-hispanics white, non-hispanics black, other hispanics and other races), education level (categorized as less than high school, complete high school or similar, higher than high school) and the poverty income ratio.

Smoking status was categorized as never $(<100$ cigarettes smoked in life and not currently smoking), former ( $\geq 100$ cigarettes in life and not currently smoking) and active smoker ( $\geq 100$ cigarettes in life and currently smoking). We calculated BMI as weight in kilograms $(\mathrm{kg})$ divided by height in meters squared $\left(\mathrm{m}^{2}\right)$.

For BP measurement, sitting SBP and DBP were determined by trained and calibrated examiners. Both $\mathrm{BP}$ measures resulted from the average of three consecutive measurements separated by a 5-min interval following a standardized protocol [28]. Average measurements of SBP and DBP were obtained from three consecutive readings. Hypertension was defined as values of SBP $\geq 140 \mathrm{mmHg}$ or DBP $\geq 90 \mathrm{mmHg}$ or the use of antihypertensive medication $[29,30]$.

Blood levels data included WBC Count $\left(10^{9} / \mathrm{L}\right)$, segmented neutrophils $\left(10^{9} / \mathrm{L}\right)$, hemoglobin A1c (HbA1c) (\%), CRP (mg/dL), vitamin B12 (pg/mL) and folate (ng/mL). Vitamin $\mathrm{B} 12$ and folate were considered given its link to the Hcy biosynthesis $[1,2]$.

\subsection{Data Management, Test Methods and Analysis}

Databases from the NHANES 2001-2002 and 2003-2004 were uploaded and treated with $\mathrm{R}$ (version for Macintosh). For the purpose of periodontal diagnosis, data was exported to a spreadsheet processor with algorithms, as previously described [31], to compute the periodontal status, PISA and PESA (as in Nesse et al. [22]). After checking for data normality and homoscedasticity, measures were reported through mean (standard deviation (SD)) for continuous variables, and a number of cases (n) and percentage (\%) for categorical variables. $T$-test was used to compare continuous measures and chi-square test to compare categorical variables according to the periodontal status (periodontitis vs. no periodontitis).

Pearson coefficient was used to assess the correlation between the Hcy and CRP with age, BMI, periodontal clinical measures (PISA and PESA), WBC, segmented neutrophils, vitamin B12 and folate. A multivariate stepwise adjusted linear regression was used to model the influence of Hcy on PISA and PESA. Model variables were selected among 
significant variables according to the periodontal status (Table 1). An initial crude model (Model 1), followed by seven progressively adjusted models were generated (Model 2Includes adjustment for Hcy and age; Model 3-Includes adjustment for Hcy, age and BMI; Model 4-Includes adjustment for Hcy, age, BMI and SBP; Model 5-Includes adjustment for Hcy, age, BMI, SBP and WBC; Model 6-Includes adjustment for Hcy, age, BMI, SBP, WBC and vitamin B12; Model 7-Includes adjustment for Hcy, age, BMI, SBP, WBC, vitamin B12 and folate; Model 8-Includes adjustment for Hcy, age, BMI, SBP, WBC, vitamin B12, folate and $\mathrm{HbA} 1 \mathrm{c})$. Multivariate stepwise adjusted linear regressions were carried out on the association of SBP and DBP with PISA or PESA (Table S2), and homocysteine levels and SBP or DBP (Table S3).

The mediating effect of PISA and PESA in the association of Hcy with SBP and DBP was carried out using the R package 'lavaan'. Mediation analysis was done through the establishment of three pathways ( $a, b$ and c) (Figure S1). Total effect (c-path) evaluated the relationship between the exposure (Hcy) and the outcomes of interest (SBP or DBP). The a-path assessed the direct effect of the exposure (Hcy) on the mediators of interest (PISA or PESA). The b-path measured the mediators (PISA or PESA) direct effect on the outcomes of interest (SBP or DBP). The mediation effect was computed through multiplying a-path with b-path. The proportion of the mediated effect was calculated using the following formula: (total effect-direct effect) $\times 100$. All mediation models have been adjusted for sociodemographic variables (age, gender, race, education), smoking habit, BMI, systemic status (number of chronic medical conditions, hypertension, diabetes mellitus, Hba1c), vitamin B12 and folate. A value of $p<0.05$ was considered significant.

\section{Results}

\subsection{Characteristics of the Study Sample}

With a primary sample of 21,161 participants, 17,140 were excluded based on the defined the inclusion criteria, thus, resulting in a final sample of 4021 patients (Figure S2). The overall characteristics of these participants are shown in Table 1. The mean age of the participants was $41.7( \pm 18.9)$ years, with balanced proportion between males and females. Participants were mostly non-hispanic black participants (48.4\%), higher education level $(47.4 \%)$ and self-reported as never smoker $(59.1 \%)$. Moreover, this sample had an average body mass index (BMI) of $27.9( \pm 7.1) \mathrm{kg} / \mathrm{m}^{2}$, indicating an average overweight population. A total of 734 participants were diagnosed as periodontitis cases (18.3\%). Periodontitis cases presented significantly differences regarding mean age, gender, race/ethnicity, education level, smoking status, family poverty ratio, Hcy mean levels, Hcy category levels, chronic medical conditions, diabetes mellitus, hypertension, BP (systolic BP (SBP) and diastolic BP (DBP)), $C$-reactive protein (CRP), periodontal inflamed surface area (PISA) and periodontal epithelial surface area (PESA) $(p<0.001)$. Mean BMI $(p=0.011)$ and folate $(p=0.040)$ were also different among periodontal groups, however, vitamin B12 was not $(p=0.880)$.

Table 1. Sample characteristics according to periodontal status $(n=4021)$.

\begin{tabular}{|c|c|c|c|c|}
\hline Variable & $\begin{array}{l}\text { No Periodontitis } \\
\quad(n=3287)\end{array}$ & $\begin{array}{l}\text { Periodontitis } \\
\quad(n=734)\end{array}$ & $p$-Value & $\begin{array}{c}\text { Overall } \\
(n=4021)\end{array}$ \\
\hline Age (years), mean (SD) & $38.4(17.8)$ & $56.8(15.8)$ & $<0.001$ & $41.7(18.9)$ \\
\hline \multicolumn{5}{|l|}{ Gender, \% (n) } \\
\hline Males & $46.2(1520)$ & $61.6(452)$ & $<0.001$ & $49.0(1972)$ \\
\hline Females & $53.8(1767)$ & $38.4(282)$ & & $51.0(2049)$ \\
\hline \multicolumn{5}{|l|}{ Race/ethnicity, \% (n) } \\
\hline Mexican American & $21.0(690)$ & $26.0(191)$ & 0.001 & $21.9(881)$ \\
\hline Non-Hispanic White & $3.4(111)$ & $4.0(29)$ & & $3.5(140)$ \\
\hline Non-Hispanic Black & $50.0(1643)$ & $41.6(305)$ & & $48.4(1948)$ \\
\hline Other Hispanic & $21.8(715)$ & $24.0(176)$ & & $22.2(891)$ \\
\hline Other races & $3.9(128)$ & $4.5(33)$ & & $4.0(161)$ \\
\hline
\end{tabular}


Table 1. Cont.

\begin{tabular}{|c|c|c|c|c|}
\hline Variable & $\begin{array}{l}\text { No Periodontitis } \\
\quad(n=3287)\end{array}$ & $\begin{array}{l}\text { Periodontitis } \\
\quad(n=734)\end{array}$ & $p$-Value & $\begin{array}{c}\text { Overall } \\
(n=4021)\end{array}$ \\
\hline \multicolumn{5}{|l|}{ Education level, \% (n) } \\
\hline$<$ High school & $24.2(797)$ & $37.9(278)$ & $<0.001$ & $26.7(1075)$ \\
\hline High school & $25.6(842)$ & $26.8(197)$ & & $25.8(1039)$ \\
\hline$>$ High school & $50.1(1647)$ & $35.1(258)$ & & $47.4(1905)$ \\
\hline \multicolumn{5}{|l|}{ Smoking status, $\%(n)$} \\
\hline Never & $63.9(2100)$ & $37.5(275)$ & $<0.001$ & $59.1(2375)$ \\
\hline Former & $18.3(603)$ & $31.5(231)$ & & $20.7(834)$ \\
\hline Current & $17.8(584)$ & $31.1(228)$ & & $20.2(812)$ \\
\hline BMI $\left(\mathrm{kg} / \mathrm{m}^{2}\right)$, mean $(\mathrm{SD})$ & $27.7(7.0)$ & $28.5(7.2)$ & 0.011 & $27.9(7.1)$ \\
\hline Hcy $(\mu \mathrm{mol} / \mathrm{L})$, mean $(\mathrm{SD})$ & $8.2(3.9)$ & $9.8(4.0)$ & $<0.001$ & $8.5(4.0)$ \\
\hline Hcy elevated level category, \% (n) & $2.8(92)$ & $6.1(45)$ & $<0.001$ & $3.4(137)$ \\
\hline $\mathrm{CRP}(\mathrm{mg} / \mathrm{dL})$, mean $(\mathrm{SD})$ & $0.4(0.8)$ & $0.5(0.8)$ & $<0.001$ & $0.4(0.8)$ \\
\hline Chronic medical conditions, mean (SD) & $0.8(1.5)$ & $1.4(2.7)$ & $<0.001$ & $0.9(1.8)$ \\
\hline Diabetes Mellitus, $n(\%)$ & $5.0(164)$ & $14.7(108)$ & $<0.001$ & $6.8(272)$ \\
\hline Hypertension, $n(\%)$ & $12.1(399)$ & $29.4(216)$ & $<0.001$ & $15.3(615)$ \\
\hline Mean SBP (mmHg), mean (SD) & $120.0(17.6)$ & $132.0(21.2)$ & $<0.001$ & $122.2(18.9)$ \\
\hline Mean DBP (mmHg), mean (SD) & $69.4(11.7)$ & $72.0(11.9)$ & $<0.001$ & $69.8(11.8)$ \\
\hline PISA $\left(\mathrm{mm}^{2}\right)$, mean $(\mathrm{SD})$ & $0.8(7.9)$ & $13.5(38.4)$ & $<0.001$ & $3.1(18.5)$ \\
\hline $\operatorname{PESA}\left(\mathrm{mm}^{2}\right)$, mean $(\mathrm{SD})$ & $17.3(51.4)$ & $118.0(107.0)$ & $<0.001$ & $35.6(75.7)$ \\
\hline Vitamin B12 (pg/mL), mean (SD) & $550.0(1120.0)$ & $554.0(521.0)$ & 0.880 & $550.9(1037.1)$ \\
\hline Folate $(\mathrm{ng} / \mathrm{mL})$, mean $(\mathrm{SD})$ & $12.6(7.8)$ & $14.6(26.3)$ & 0.040 & $12.9(13.3)$ \\
\hline
\end{tabular}

<-less; >-higher; BMI-Body Mass Index; CRP—C-Reactive Protein; DBP—Diastolic Blood Pressure; Hcy-Homocysteine; n-number of cases; PESA-Periodontal Epithelial Surface Area; PISA-Periodontal Inflamed Surface Area; SBP-Systolic Blood Pressure; SDStandard Deviation.

\subsection{Correlation Estimates of Hcy Compared to CRP}

To understand if Hcy and CRP displayed alike behavior with similar variables, we investigated the correlation of Homocysteine and CRP with relevant continuous variables (Table 2). In the Hcy levels, age had a moderate correlation effect $(p<0.001)$, while SBP, DBP, PISA and PESA had a mild correlation effect $(p<0.001)$. Furthermore, we confirmed the association of Hcy levels with vitamin B12 and folate $(p<0.001)$. In the overall sample, CRP had a significantly mild correlation with BMI $(p<0.001)$, white blood cells (WBC) counts $(p<0.001)$, segmented neutrophils $(p<0.001)$ and age $(p<0.05)$. The correlations between PISA and PESA with SBP and DBP were graphically displayed $(p<0.01)$ (Figure 1$)$.

Table 2. Correlation of CRP and Hcy with sociodemographic and clinical variables $(n=4021)$.

\begin{tabular}{ccc}
\hline Variable & CRP $(\mathrm{mg} / \mathrm{dL})$ & Homocysteine $(\mu \mathrm{mol} / \mathrm{L})$ \\
\hline Age $(\mathrm{years})$ & $0.036^{*}$ & $0.326^{* *}$ \\
Hcy $(\mu \mathrm{mol} / \mathrm{L})$ & -0.019 & - \\
BMI $\left(\mathrm{g} / \mathrm{m}^{2}\right)$ & $0.215^{* *}$ & 0.003 \\
SBP $(\mathrm{mmHg})$ & $0.037^{*}$ & $0.274^{* *}$ \\
DBP $\left(\mathrm{mmHg}^{*}\right)$ & 0.015 & $0.124^{* *}$ \\
PISA $\left(\mathrm{mm}^{2}\right)$ & 0.030 & $0.054^{* *}$ \\
PESA $\left(\mathrm{mm}^{2}\right)$ & 0.031 & $0.177^{* *}$ \\
WBC $\left(10^{9} / \mathrm{L}\right)$ & $0.154^{* *}$ & $-0.026^{*}$ \\
Segmented Neutrophils $\left(10^{9} / \mathrm{L}\right)$ & $0.143^{* *}$ & $-0.035^{*}$ \\
Vitamin B12 $(\mathrm{pg} / \mathrm{mL})$ & 0.006 & $-0.058^{* *}$ \\
Folate $(\mathrm{ng} / \mathrm{mL})$ & -0.011 & $-0.045^{* *}$
\end{tabular}

Pearson correlation, ${ }^{*} p<0.05,{ }^{* *} p<0.001$. BMI-Body Mass Index; CRP-C-reactive Protein; DBP-Diastolic Blood Pressure; Hcy-Homocysteine; PISA—Periodontal Inflamed Surface Area; PESA—Periodontal Epithelial Surface Area; SBP-Systolic Blood Pressure; WBC-White blood cells counts. 
a
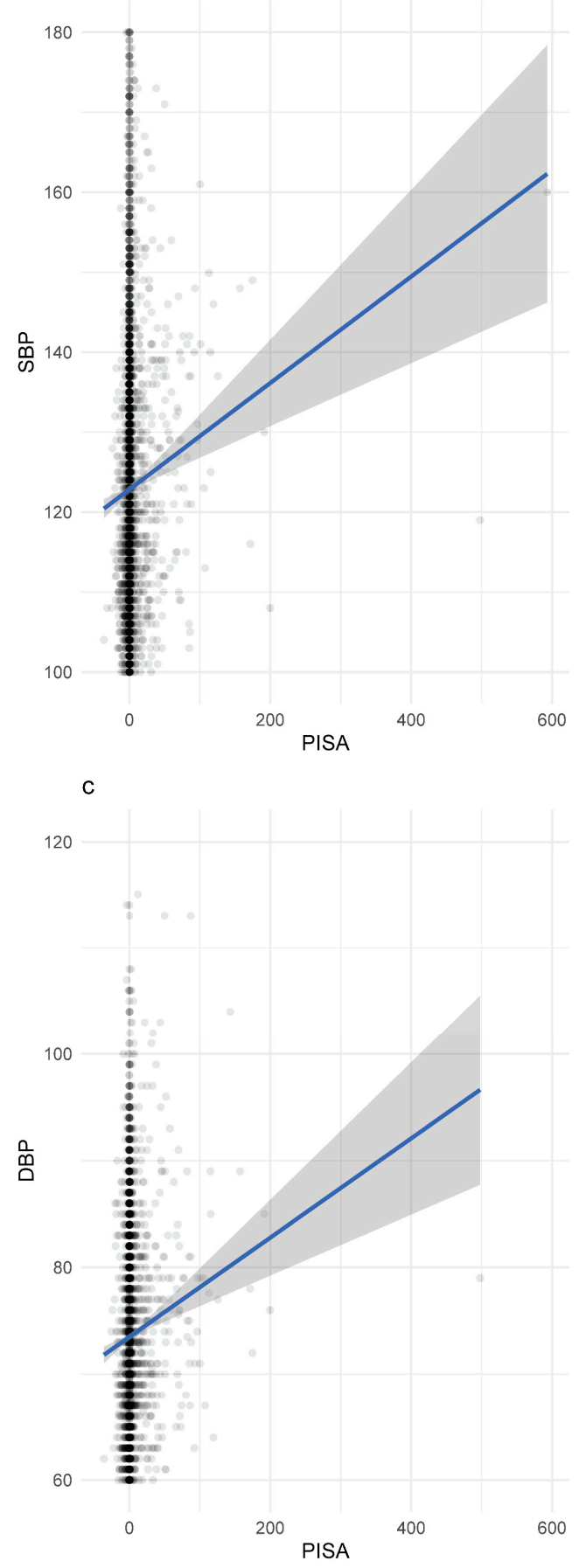

b

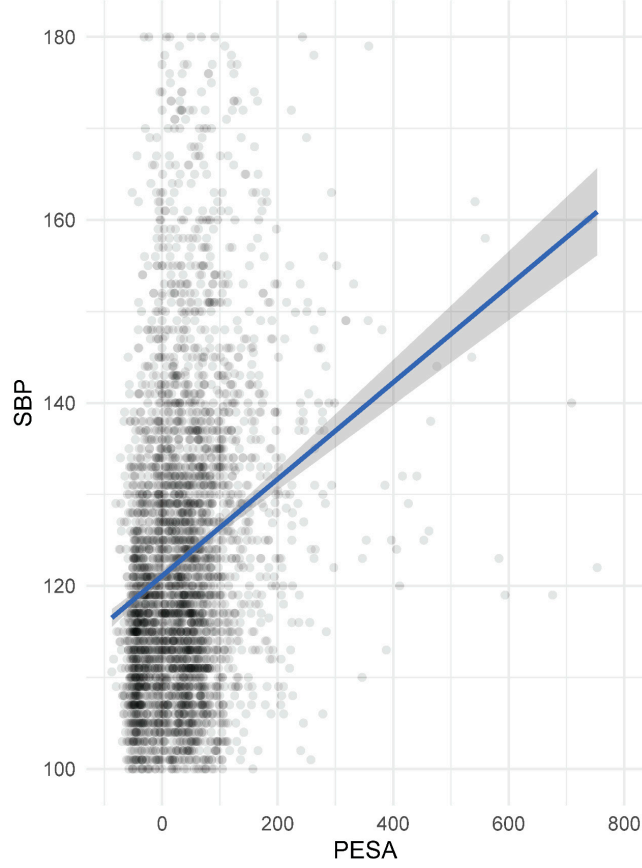

d

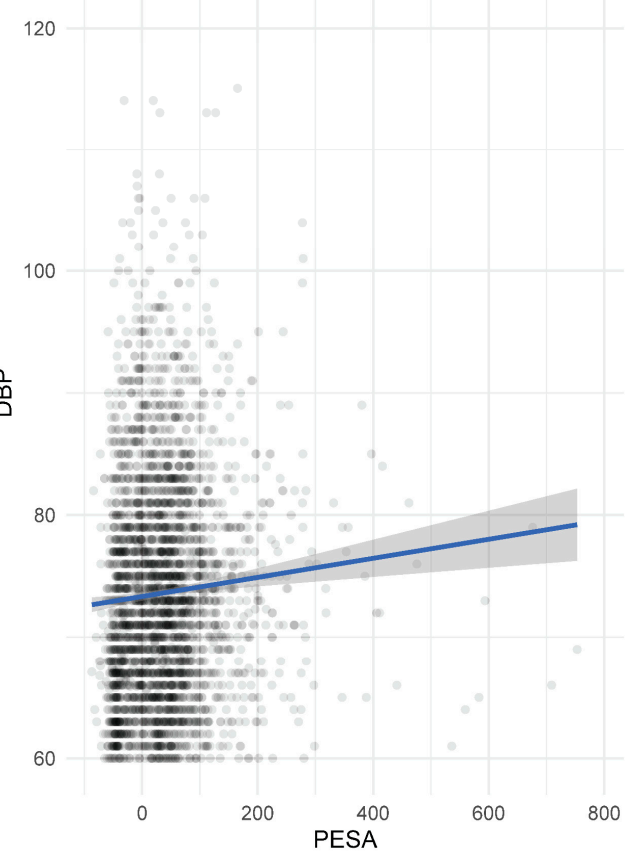

Figure 1. Scatterplots displaying the correlation between PISA with SBP (a) and DBP (c), and PESA with SBP (b) and $\operatorname{DBP}(\mathbf{d})$.

Next, we examined the linear relationship of Hcy with PISA and PESA in crude (Model 1) and adjusted models (Models 2-8) (Table 3). Linear regression models confirmed that PISA is significantly associated with Hcy $(p<0.001)$ however, that not occurred in the adjusted models. While for PESA, both for the crude and adjusted models, it was significantly associated with Hcy $(p<0.01)$. The linear association of SBP and DBP with PISA and PESA was also carried out (Table S1), with DBP being associated with PISA in all adjusted models. The linear association of Hcy with SBP and DBP was found to be significant in all adjusted models (Table S2). 
Table 3. Crude and adjusted linear regression models of homocysteine levels and PISA or PESA for the overall sample with the respective B coefficient and standard error (SE) $(n=4021)$.

\begin{tabular}{ccc}
\hline & \multicolumn{2}{c}{ Homocysteine } \\
\cline { 2 - 3 } Model & PISA & PESA \\
\hline 1 & $0.012 * *(0.003)$ & $0.009 *(0.001)$ \\
2 & $0.005(0.003)$ & $0.002 *(0.001)$ \\
3 & $0.005(0.003)$ & $0.002 *(0.001)$ \\
4 & $0.004(0.003)$ & $0.002 *(0.001)$ \\
5 & $0.004(0.003)$ & $0.002 *(0.001)$ \\
6 & $0.004(0.003)$ & $0.002 *(0.001)$ \\
7 & $0.003(0.003)$ & $0.002 *(0.001)$ \\
8 & $0.003(0.003)$ & $0.002 *(0.001)$ \\
\hline
\end{tabular}

Values are presented as B coefficient (SE). PISA—Periodontal Inflamed Surface Area; PESA—Periodontal Epithelial Surface Area. Model 1-Unadjusted model for Hcy; Model 2-Includes adjustment for Hcy and age; Model 3-Includes adjustment for Hcy, age and BMI; Model 4-Includes adjustment for Hcy, age, BMI and SBP; Model 5-Includes adjustment for Hcy, age, BMI, SBP and WBC; Model 6-Includes adjustment for Hcy, age, BMI, SBP, WBC and vitamin B12; Model 7-Includes adjustment for Hcy, age, BMI, SBP, WBC, vitamin B12 and folate; Model 8-Includes adjustment for Hcy, age, BMI, SBP, WBC, vitamin B12, folate and HbA1c (\%). ${ }^{*} p<0.01$; ** $p<0.001$.

\subsection{Mediation Analyses}

There was evidence that the association between Hcy with BP (SBP and DBP) were mediated by PISA and PESA. Mediation analyses demonstrated that PISA was estimated to mediate $17.39 \%$ and $16.33 \%$ of the total association between Hcy with SBP and DBP, respectively $(p<0.001)$ (Table 4$)$. Furthermore, PESA was estimated to mediate $0.89 \%$ and $47.20 \%$ of the total association between Hcy with SBP and DBP, respectively $(p<0.001)$ (Tables 4 and 5).

Table 4. Mediation analysis of the effects of PISA and PESA on the association of Hcy levels with SBP $(n=4021)$.

\begin{tabular}{|c|c|c|c|}
\hline \multicolumn{4}{|c|}{ Exposure: Hcy/Outcome: SBP Mediator: PISA } \\
\hline Effect & Estimate & SE & $p$-value \\
\hline a (exposure $\rightarrow$ mediator) & 0.156 & 0.076 & 0.041 \\
\hline b (mediator $\rightarrow$ outcome) & 0.076 & 0.017 & $<0.001$ \\
\hline$c$ (total effect) & 0.069 & 0.006 & $<0.001$ \\
\hline$c^{\prime}$ (direct effect) & 0.012 & 0.003 & $<0.001$ \\
\hline ab (mediated effect) & 0.012 & 0.006 & $<0.001$ \\
\hline \multicolumn{4}{|c|}{$\mathrm{ab} / \mathrm{c}($ PISA percentage mediated $)=17.4 \%$} \\
\hline \multicolumn{4}{|c|}{ Exposure: Hcy/Outcome: SBP Mediator: PESA } \\
\hline Effect & Estimate & SE & $p$-value \\
\hline a (exposure $\rightarrow$ mediator) & 0.006 & 0.001 & $<0.001$ \\
\hline b (mediator $\rightarrow$ outcome) & 1.176 & 0.074 & $<0.001$ \\
\hline$c($ total effect $)$ & 0.900 & 0.063 & $<0.001$ \\
\hline$c^{\prime}$ (direct effect) & 0.892 & 0.063 & $<0.001$ \\
\hline $\mathrm{ab}$ (mediated effect) & 0.008 & 0.001 & $<0.001$ \\
\hline
\end{tabular}

$\mathrm{ab} / \mathrm{c}$ (PISA percentage mediated) $=0.9 \%$

PISA—Periodontal Inflamed Surface Area; PESA—Periodontal Epithelial Surface Area; SBP—Systolic Blood Pressure. Models adjusted for sociodemographic variables (age, gender, race, education), smoking habit, BMI, systemic status (number of chronic medical conditions, diabetes mellitus, hemoglobin A1c [HbA1c]), vitamin B12 and folate. Abbreviations: Hcy—homocysteine; PISA—Periodontal Inflamed Surface Area; PESA-Periodontal Epithelial Surface Area; SBP-Systolic Blood Pressure. 
Table 5. Mediation analysis of the effects of PISA and PESA on the association of Hcy levels with DBP $(n=4021)$.

\begin{tabular}{|c|c|c|c|}
\hline \multicolumn{4}{|c|}{ Exposure: Hcy/Outcome: DBP Mediator: PISA } \\
\hline Effect & Estimate & SE & $p$-value \\
\hline a (exposure $\rightarrow$ mediator) & 0.219 & 0.074 & 0.003 \\
\hline $\mathrm{b}$ (mediator $\rightarrow$ outcome) & 0.035 & 0.010 & 0.001 \\
\hline$c($ total effect $)$ & 0.049 & 0.006 & $<0.001$ \\
\hline$c^{\prime}($ direct effect $)$ & 0.041 & 0.005 & $<0.001$ \\
\hline ab (mediated effect) & 0.008 & 0.003 & 0.017 \\
\hline \multicolumn{4}{|c|}{$\mathrm{ab} / \mathrm{c}($ PISA percentage mediated $)=16.3 \%$} \\
\hline \multicolumn{4}{|c|}{ Exposure: Hcy/Outcome: DBP Mediator: PESA } \\
\hline Effect & Estimate & SE & $p$-value \\
\hline a (exposure $\rightarrow$ mediator) & 3.222 & 0.297 & $<0.001$ \\
\hline $\mathrm{b}$ (mediator $\rightarrow$ outcome) & 0.011 & 0.002 & $<0.001$ \\
\hline$c($ total effect $)$ & 0.072 & 0.009 & $<0.001$ \\
\hline$c^{\prime}$ (direct effect) & 0.038 & 0.005 & $<0.001$ \\
\hline ab (mediated effect) & 0.034 & 0.008 & $<0.001$ \\
\hline
\end{tabular}

$\mathrm{ab} / \mathrm{c}$ (PISA percentage mediated) $=47.2 \%$

PISA-Periodontal Inflamed Surface Area; PESA—Periodontal Epithelial Surface Area; DBP—Diastolic Blood Pressure. Models adjusted for sociodemographic variables (age, gender, race, education), smoking habit, BMI, systemic status (number of chronic medical conditions, diabetes mellitus, hemoglobin A1c [HbA1c]), vitamin B12 and folate. Abbreviations: Hcy—homocysteine; PISA-Periodontal Inflamed Surface Area; PESA—Periodontal Epithelial Surface Area; DBP—Diastolic Blood Pressure.

\section{Discussion}

In this exploratory study, we found periodontitis cases to present higher Hcy levels, and this association showed significance even when adjusted for multiple confounding variables. Moreover, two periodontal parameters (PISA and PESA) demonstrated to have potential mediating effect in the link between Hcy and BP. These findings may support an association between Hcy and periodontitis.

Overall, these results, in our view, are novel because they suggest that such association may rely more on the destruction of periodontal tissues (PESA) rather than inflamed surface area (PISA). That is to say, PESA as a reflection of the subgingival space harboring bacteria underlines the greater importance of the area of bacterial colonization and its increase during periodontal destruction in this association. The bacterial role related to methionine pathways is based on the production of volatile sulfur compounds by periodontal bacteria, causing the commonly detected malodor in periodontal patients [32-34]. At this stage, these results only highlight a possible connection point, and the reader must bear in mind that they are solely hypothetical. Though, the invasion of periodontal bacteria through the ulcerated epithelium into the blood stream has been shown, with eventual hostile systemic consequences [35,36].

In fact, Hcy was initially proposed in periodontal medicine as a candidate in the link of periodontal with cardiovascular conditions [10]. Comprehensively, Hcy inhibits nitric oxide in the endothelium affecting its vasodilation function and leads to excessive reactive oxygen radicals in the myocardium [8,9]. The elevated serum levels of Hcy result, therefore, in a higher risk for endothelial cell injury by inducing apoptotic cell death of endothelial cells and smooth muscle cells [37,38], and is collectively seen as an inflammatory reaction in the blood vessels [39]. Furthermore, periodontitis was proposed to affect vascular function through boosted systemic inflammation and bacteremia, instigating vascular damage (by increased cytokines, immune cells, nitric oxide and reactive oxygen species) [16]. Such as Hcy, periodontal bacteria have been shown to decrease the bioavailability of nitric oxide [40] and this biological pathway may be a starting point in this association.

In this sense and given the cross-sectional nature of this study (also discussed later), we cannot discern whether this is a unilateral (and triggered by Hcy or periodontitis) or bilateral nature. On the one hand, untreated periodontitis further inflammatory burden 
that has been shown to increase the risk towards cardiovascular disease [41]. On the other hand, indirect evidence from a clinical trial demonstrated that adjunctive folate during periodontal treatment reduced plasma Hcy, yet with unknown biological reasons and long-term clinical consequences (i.e., reduced risk of high BP) [42].

Another important mechanistic nexus can be oxidative stress, which is related to both hyperhomocysteinemia [43] and periodontitis [44]. In both circumstances, reactive oxygen species are overproduced and cause unbalanced milieus causing tissue damage [43,44]. Nevertheless, we were not able to explore further this as the NHANES does not provide suitable variables representing oxidative stress, and this is a matter to address in the future.

\section{Strengths and Limitations}

The present cross-sectional study has specific fallouts worth examining. The observational nature of NHANES precluded any inference of causality or temporal link. Furthermore, information regarding systemic inflammation was limited as CRP levels were the only recognized and accepted hallmark available, thus limiting the validity of these results. For this reason, data on other important markers of inflammation, such as cytokines (Tumor Necrosis Factor- $\alpha$ and interleukins) might be of interest to study in future studies.

When exploring the association and mediation effect, these results should be interpreted cautiously. However, previous studies have contributed to support a conceivable causal link between Hcy and periodontitis as studies have found higher levels of Hcy in periodontitis cases [13-15,42] and a randomized intervention trial demonstrated the effectiveness of periodontal treatment in reducing Hcy levels [42]. Although, studies with small samples have reported this association $[13,14]$, our study may stand-out from the others by the considerable increase in participants. Furthermore, this sample is based on two consecutive NHANES waves, and are representative of the American population. The number of covariates included in our analyses were comprehensive.

The periodontal assessment was made by calibrated examiners yet a partial-mouth protocol has been taken place, which may contribute to less accurate and precise results $[31,45]$. Despite this, our estimates revealed very interesting values of both correlation and mediation.

\section{Conclusions}

Hcy serum levels are associated with the periodontal status. Hcy levels demonstrated more relationship with PISA and PESA, BP and age. Compared to CRP, Hcy showed different associations. Besides, PISA and PESA might play a mediation effect on the link between Hcy and BP.

Supplementary Materials: The following are available online at https:/ / www.mdpi.com/article/10 .3390 / biom11060875/s1, Figure S1: Participant's flowchart, Figure S2: Path diagram of the mediation analysis models, Table S1: Crude and adjusted linear regression models of SBP and DBP with PISA or PESA for the overall sample with the respective B coefficient and standard error (SE) $(n=4021)$, Table S2: Crude and adjusted linear regression models of homocysteine levels and SBP or DBP for the overall sample with the respective B coefficient and standard error (SE) $(n=4021)$, Table S3: Strobe statement-Checklist of items that should be included in reports of case-control studies.

Author Contributions: Conceptualization, J.B. and V.M.; methodology, J.B. and V.M.; formal analysis, J.B.; investigation, J.B. and V.M.; data curation, J.B.; writing—original draft preparation, J.B. and V.M., Y.L., L.P., J.J.M.; writing-review and editing, J.B. and V.M., Y.L., L.P., J.J.M. All authors have read and agreed to the published version of the manuscript.

Funding: This work is financed by national funds through the FCT-Foundation for Science and Technology, I.P., under the project UIDB/04585/2020. Yago Leira holds a research contract with Fundación Instituto de Investigación Sanitaria de Santiago de Compostela and a Senior Clinical Research Fellowship supported by the UCL Biomedical Research Centre who receives funding from the National Institute for Health Research (NIHR-INF-0387).

Institutional Review Board Statement: Not applicable. 
Informed Consent Statement: Informed consent was obtained from all subjects involved in the study.

Data Availability Statement: Data will be provided upon reasonable request.

Acknowledgments: We acknowledge the NHANES investigators and personnel.

Conflicts of Interest: The authors declare no conflict of interest.

\section{References}

1. Škovierová, H.; Vidomanová, E.; Mahmood, S.; Sopková, J.; Drgová, A.; Červeňová, T.; Halašová, E.; Lehotský, J. The Molecular and Cellular Effect of Homocysteine Metabolism Imbalance on Human Health. Int. J. Mol. Sci. 2016, 17, 1733. [CrossRef]

2. Al Mutairi, F. Hyperhomocysteinemia: Clinical Insights. J. Cent. Nerv. Syst. Dis. 2020, 12, 117957352096223. [CrossRef]

3. Refsum, H.; Smith, A.D.; Ueland, P.M.; Nexo, E.; Clarke, R.; McPartlin, J.; Johnston, C.; Engbaek, F.; Schneede, J.; McPartlin, C.; et al. Facts and Recommendations about Total Homocysteine Determinations: An Expert Opinion. Clin. Chem. 2004, 50, 3-32. [CrossRef]

4. Perła-Kaján, J.; Twardowski, T.; Jakubowski, H. Mechanisms of Homocysteine Toxicity in Humans. Amino Acids 2007, 32, 561-572. [CrossRef]

5. Kang, S.S.; Wong, P.W.K.; Malinow, M.R. Hyperhomocyst(e)Inemia as a Risk Factor for Occlusive Vascular Disease. Annu. Rev. Nutr. 1992, 12, 279-298. [CrossRef]

6. McCully, K.S. Chemical Pathology of Homocysteine I. Atherogenesis. Ann. Clin. Lab. Sci. 1993, 23, 477-493. [PubMed]

7. Wald, D.S.; Morris, J.K.; Law, M.; Wald, N.J. Folic Acid, Homocysteine, and Cardiovascular Disease: Judging Causality in the Face of Inconclusive Trial Evidence Evidence from Patients with Homocystinuria. BMJ 2006, 333, 1114-1117. [CrossRef]

8. Stühlinger, M.C.; Tsao, P.S.; Her, J.H.; Kimoto, M.; Balint, R.F.; Cooke, J.P. Homocysteine Impairs the Nitric Oxide Synthase Pathway Role of Asymmetric Dimethylarginine. Circulation 2001, 104, 2569-2575. [CrossRef]

9. Fournier, P.; Fourcade, J.; Roncalli, J.; Salvayre, R.; Galinier, M.; Caussé, E. Homocysteine in Chronic Heart Failure. Clin. Lab. 2015, 61. [CrossRef]

10. Kornman, K.S.; Duff, G.W. Candidate Genes as Potential Links between Periodontal and Cardiovascular Diseases. Ann. Periodontol./Am. Acad. Periodontol. 2001, 6, 48-57. [CrossRef]

11. Darveau, R.P. Periodontitis: A Polymicrobial Disruption of Host Homeostasis. Nat. Rev. Microbiol. 2010, 8, 481-490. [CrossRef]

12. Hajishengallis, G. Periodontitis: From Microbial Immune Subversion to Systemic Inflammation. Nat. Rev. Immunol. 2015, 15, 30-44. [CrossRef]

13. Montebugnoli, L.; Servidio, D.; Miaton, R.A.; Prati, C.; Tricoci, P.; Melloni, C. Poor Oral Health Is Associated with Coronary Heart Disease and Elevated Systemic Inflammatory and Haemostatic Factors. J. Clin. Periodontol. 2004, 31, 25-29. [CrossRef]

14. Joseph, R.; Nath, S.G.; Joseraj, M.G. Elevated Plasma Homocysteine Levels in Chronic Periodontitis: A Hospital-Based CaseControl Study. J. Periodontol. 2011, 82, 439-444. [CrossRef] [PubMed]

15. Bhardwaj, S.; Prabhuji, M.L.V.; Karthikeyan, B.V. Effect of Non-Surgical Periodontal Therapy on Plasma Homocysteine Levels in Indian Population with Chronic Periodontitis: A Pilot Study. J. Clin. Periodontol. 2015, 42, 221-227. [CrossRef]

16. Muñoz Aguilera, E.; Suvan, J.; Buti, J.; Czesnikiewicz-Guzik, M.; Barbosa Ribeiro, A.; Orlandi, M.; Guzik, T.J.; Hingorani, A.D.; Nart, J.; D'Aiuto, F. Periodontitis Is Associated with Hypertension: A Systematic Review and Meta-Analysis. Cardiovasc. Res. 2020, 116, 28-39. [CrossRef] [PubMed]

17. NHANES Questionnaires, Datasets, and Related Documentation. Available online: https://wwwn.cdc.gov/nchs/nhanes/ (accessed on 6 March 2021).

18. Lachat, C.; Hawwash, D.; Ocké, M.C.; Berg, C.; Forsum, E.; Hörnell, A.; Larsson, C.; Sonestedt, E.; Wirfält, E.; Åkesson, A.; et al. Strengthening the Reporting of Observational Studies in Epidemiology—Nutritional Epidemiology (STROBE-Nut): An Extension of the STROBE Statement. PLOS Med. 2016, 13, e1002036. [CrossRef]

19. Dye, B.A.; Thornton-Evans, G. A Brief History of National Surveillance Efforts for Periodontal Disease in the United States. J. Periodontol. 2007, 78, 1373-1379. [CrossRef] [PubMed]

20. Eke, P.I.; Page, R.C.; Wei, L.; Thornton-Evans, G.; Genco, R.J. Update of the Case Definitions for Population-Based Surveillance of Periodontitis. J. Periodontol. 2012, 83, 1449-1454. [CrossRef]

21. Hujoel, P.P.; White, B.A.; García, R.I.; Listgarten, M.A. The Dentogingival Epithelial Surface Area Revisited. J. Periodontal. Res. 2001, 36, 48-55. [CrossRef] [PubMed]

22. Nesse, W.; Abbas, F.; Van Der Ploeg, I.; Spijkervet, F.K.L.; Dijkstra, P.U.; Vissink, A. Periodontal Inflamed Surface Area: Quantifying Inflammatory Burden. J. Clin. Periodontol. 2008, 35, 668-673. [CrossRef]

23. NHANES 2001-2002 Data Documentation, Codebook, and Frequencies. Available online: https:/ /wwwn.cdc.gov/Nchs/Nhanes/ 2001-2002/L06_2_B.htm (accessed on 10 November 2020).

24. Shipchandler, M.; Moore, E. Rapid, Fully Automated Measurement of Plasma Homocyst(e)Ine with the Abbott IMx Analyzer. Clin. Chem. 1995, 41, 991-994. [CrossRef]

25. NHANES 2003-2004 Data Documentation, Codebook, and Frequencies. Available online: https://wwwn.cdc.gov/Nchs/Nhanes/ 2003-2004/L06MH_C.htm (accessed on 10 November 2020).

26. Boushey, C.J.; Beresford, S.A.; Omenn, G.S.; Motulsky, A.G. A Quantitative Assessment of Plasma Homocysteine as a Risk Factor for Vascular Disease. Probable Benefits of Increasing Folic Acid Intakes. JAMA 1995, 274, 1049-1057. [CrossRef] 
27. Ueland, P.M.; Refsum, H.; Stabler, S.P.; Malinow, M.R.; Andersson, A.; Allen, R.H. Total Homocysteine in Plasma or Serum: Methods and Clinical Applications. Clin. Chem. 1993, 39, 1764-1779. [CrossRef]

28. Ostchega, Y.; Prineas, R.J.; Paulose-Ram, R.; Grim, C.M.; Willard, G.; Collins, D. National Health and Nutrition Examination Survey 1999-2000: Effect of Observer Training and Protocol Standardization on Reducing Blood Pressure Measurement Error. J. Clin. Epidemiol. 2003, 56, 768-774. [CrossRef]

29. Williams, B.; Mancia, G.; Spiering, W.; Agabiti Rosei, E.; Azizi, M.; Burnier, M.; Clement, D.L.; Coca, A.; de Simone, G.; Dominiczak, A.; et al. 2018 ESC/ESH Guidelines for the Management of Arterial Hypertension: The Task Force for the Management of Arterial Hypertension of the European Society of Cardiology and the European Society of Hypertension: The Task Force for the Management of Arterial Hypertension of the European Society of Cardiology and the European Society of Hypertension. J. Hypertens 2018, 36, 1953-2041. [CrossRef]

30. Mills, K.T.; Bundy, J.D.; Kelly, T.N.; Reed, J.E.; Kearney, P.M.; Reynolds, K.; Chen, J.; He, J. Global Disparities of Hypertension Prevalence and Control: A Systematic Analysis of Population-Based Studies From 90 Countries. Circulation 2016, 134, 441-450. [CrossRef]

31. Botelho, J.; Machado, V.; Proença, L.; Mendes, J.J. The 2018 Periodontitis Case Definition Improves Accuracy Performance of Full-Mouth Partial Diagnostic Protocols. Sci. Rep. 2020, 10, 7093. [CrossRef]

32. Nakano, Y.; Yoshimura, M.; Koga, T. Correlation between Oral Malodor and Periodontal Bacteria. Microbes Infect. 2002 , 4, 679-683. [CrossRef]

33. Ryder, M.I. Comparison of Neutrophil Functions in Aggressive and Chronic Periodontitis. Periodontology 2000 2010, 53, 124-137. [CrossRef]

34. Yaegaki, K.; Sanada, K. Biochemical and Clinical Factors Influencing Oral Malodor in Periodontal Patients. J. Periodontol. 1992, 63, 783-789. [CrossRef]

35. Botelho, J.; Machado, V.; Hussain, S.B.; Zehra, S.A.; Proença, L.; Orlandi, M.; Mendes, J.J.; D'Aiuto, F. Periodontitis and Circulating Blood Cell Profiles: A Systematic Review and Meta-Analysis. Exp. Hematol. 2021, 93, 1-13. [CrossRef]

36. Kinane, D.F.; Stathopoulou, P.G.; Papapanou, P.N. Periodontal Diseases. Nat. Rev. Dis. Primers 2017, 3, 17038. [CrossRef]

37. Hossain, G.S.; van Thienen, J.V.; Werstuck, G.H.; Zhou, J.; Sood, S.K.; Dickhout, J.G.; de Koning, A.B.L.; Tang, D.; Wu, D.; Falk, E.; et al. TDAG51 Is Induced by Homocysteine, Promotes Detachment-Mediated Programmed Cell Death, and Contributes to the Cevelopment of Atherosclerosis in Hyperhomocysteinemia. J. Biol. Chem. 2003, 278, 30317-30327. [CrossRef]

38. Zhang, C.; Cai, Y.; Adachi, M.T.; Oshiro, S.; Aso, T.; Kaufman, R.J.; Kitajima, S. Homocysteine Induces Programmed Cell Death in Human Vascular Endothelial Cells through Activation of the Unfolded Protein Response. J. Biol. Chem. 2001, 276, 35867-35874. [CrossRef]

39. Ganguly, P.; Alam, S.F. Role of Homocysteine in the Development of Cardiovascular Disease. Nutr. J. 2015, 14. [CrossRef]

40. Velsko, I.M.; Chukkapalli, S.S.; Rivera, M.F.; Lee, J.-Y.; Chen, H.; Zheng, D.; Bhattacharyya, I.; Gangula, P.R.; Lucas, A.R.; Kesavalu, L. Active Invasion of Oral and Aortic Tissues by Porphyromonas Gingivalis in Mice Causally Links Periodontitis and Atherosclerosis. PLoS ONE 2014, 9, e97811. [CrossRef] [PubMed]

41. Holmlund, A.; Lampa, E.; Lind, L. Poor Response to Periodontal Treatment May Predict Future Cardiovascular Disease. J. Dent. Res. 2017, 96, 768-773. [CrossRef]

42. Keceli, H.G.; Ercan, N.; Karsiyaka Hendek, M.; Kisa, U.; Mesut, B.; Olgun, E. The Effect of the Systemic Folic Acid Intake as an Adjunct to Scaling and Root Planing on Clinical Parameters and Homocysteine and C-Reactive Protein Levels in Gingival Crevicular Fluid of Periodontitis Patients: A Randomized Placebo-Controlled Clinical t. J. Clin. Periodontol. 2020, 47, 602-613. [CrossRef]

43. Tyagi, N.; Sedoris, K.C.; Steed, M.; Ovechkin, A.V.; Moshal, K.S.; Tyagi, S.C. Mechanisms of Homocysteine-Induced Oxidative Stress. Am. J. Physiol. Heart Circ. Physiol. 2005, 289, H2649-H2656. [CrossRef]

44. Wang, Y.; Andrukhov, O.; Rausch-Fan, X. Oxidative Stress and Antioxidant System in Periodontitis. Front. Physiol. 2017, 8, 910. [CrossRef] [PubMed]

45. Machado, V.; Botelho, J.; Mascarenhas, P.; Cavacas, M.A.; Alves, R.; Mendes, J.J. Partial Recording Protocols Performance on the Assessment of Periodontitis Severity and Extent: Bias Magnitudes, Sensibility, and Specificity. Rev. Port. De Estomatol. Med. Dent. E Cir. Maxilofac. 2018, 59, 145-153. [CrossRef] 